\title{
JOURNAL OF HEALTH SCIENCES AND MEDICINE
}

\section{Sağlık Bilimleri ve Tıp Dergisi}

\author{
J Health Sci Med 2019; 2(3): 102-106
}

Case Report / Olgu Sunumu

\section{Oruç ibadeti ve diyabet: olgu örnekleriyle bakış}

\section{Ramadan fasting and diabetes: view with the case reports}

\author{
(1) Merve Lehimcioğlu', (ㅇ) İrfan Karahan ${ }^{1}$, (1) Aşkın Güngüneş², (1) Aydın Çifci ${ }^{1}$ \\ ${ }^{1}$ Kırıkkale Üniversitesi Tıp Fakültesi İç Hastalıkları Anabilim Dalı, Kırıkkale, Türkiye \\ ${ }^{2}$ Kırıkkale Üniversitesi Tıp Fakültesi İç Hastalıkları Anabilim Dalı, Endokrinoloji Bilim Dalı, Kırıkkale, Türkiye
}

\begin{abstract}
ÖZ
İslamiyet dışında Hıristiyanlık, Yahudilik gibi semavi dinlerde ve Hinduizm, Budizm gibi daha pek çok dinde oruç ibadeti vardır. Hıristiyanlarda da İslamiyet'te olduğu gibi yılın belli dönemlerinde farz ibadet olarak geçmektedir. Tüm dünyada Ramazan ayında 1,5 milyar kişinin oruç tuttuğu tahmin edilmektedir. Ülkelere ve oruç tutulan mevsimlere göre oruçlu olunan süre 9-21 saat arasında değişebilmektedir. Bazı hastalar hekime danışıp hekim kontrolünde oruç tutmakta veya bazı hastalara da hekim tarafindan oruç tutmaması gerektiğ söylenmektedir. Ama en önemlisi bazı hastalar hiç hekime danışmadan oruç tutmakta ve ciddi sağlık problemleriyle karşılaşmaktadırlar. Oruçla ilgili yapılan çalışmalar arttıkça pek çok hasta grubunun hekim kontrolünde ve düzenli takiplerine gelerek güvenle oruç tutabildiği pek çok çalıșmada gösterilmiştir. Biz de bu yazıda kendi isteği ile oruç tutacağını beyan eden ve oruç tutan üç tip 2 diyabet hastasının takip sonuçlarını paylaşmak istedik.

Anahtar Kelimeler: Ramazan, oruç, diyabet
\end{abstract}

\section{GíRiş}

İslamiyet dışında Hıristiyanlık, Yahudilik gibi semavi dinlerde ve Hinduzim, Budizm gibi daha pek çok dinde oruç ibadeti vardır. Hıristiyanlarda da İslamiyet'te olduğu gibi yılın belli dönemlerinde farz ibadet olarak geçmektedir. Tüm dünyada Ramazan ayında 1,5 milyar kişinin oruç tuttuğu tahmin edilmektedir. Türkiye'de 2018 yılında yaklaşık 17 saat oruç tutulurken, İskandinavya ülkelerinde bu süre 21 saat civarı ile çok uzun ve Arjantin'de ise 9

\section{ABSTRACT}

Apart from Islam, Christianity, Judaism, and many other religions such as Hinduism, Buddhism have fast worship, and Christians also have worshiped in certain periods of the year as in Islam. It is estimated that 1.5 billion people fasted all over the world during Ramadan. According to the countries and the fasting season, the period of fasting can vary between 9-21 hours. Some patients are told that they should not consult fasting physicians and fasting under physician control, or that some patients should not fast by the physician. But most importantly, some patients are fasting without medication consultation and face serious health problems. As the studies about fasting increase, many studies have shown that many patients can safely fast by physician control and regular follow-ups. We also wanted to share the follow-up results of three types of diabetic patients reporting fasting and fasting in this article at their own discretion.

Keywords: Ramadan, fasting, diabetes

saat 20 dakika ile çok kısadır. Ülkemizde toplumun yaklaşık 2/3'ünün oruç tuttuğu tahmin edilmektedir $(1,2)$.

İslamiyet'te dinin şartları arasında yer almakta olduğundan dolayı bazen kişiler kendini zorlayarak ve sağlığını riske atarak ne pahasına olursa olsun oruç tutmaktadırlar. Bazı hastalar hekime danışıp hekim kontrolünde oruç tutmakta veya bazı hastalara da hekim tarafından oruç tutmaması gerektiği söylenmektedir. Artık oral antidiyabetik kullanan ve

Sorumlu Yazar: Aydın Çifci, Kırıkkale Üniversitesi Tıp Fakültesi İç Hastalıkları Anabilim Dalı, 71450, Yahşihan, Kırıkkale, Türkiye

E-posta: dr.aydin.71@hotmail.com

Geliş Tarihi: 29.06.2018 Kabul Tarihi: 28.07.2018 Doi: 10.32322/jhsm.439193

Cite this article as: Lehimcioğlu M, Karahan I, Güngüneş A, Çifci A. Oruç ibadeti ve diyabet: olgu örnekleriyle baklş. J Health Sci Med 2019; 2(3): 102-106. 
komorbit ciddi hastalığ 1 (serebrovasküler olay, ciddi kalp yetmezliği, aritmi, ileri böbrek yetmezliği gibi) olmayan, kan şekeri kontrol altında olan tip 2 diyabetes mellitus (DM) hastalarının oruç tutabileceği pek çok kılavuzda belirtilmektedir. Ayrıca insülin kullanan ve önemli komorbiditesi olmayan uygun hastaların da gerekli tedbirler alınmak ve yakın takip altında tutulmak şartıyla güvenle oruç tutabileceğine dair kanıtlar giderek artmaktadır $(3,4)$.

Tip 2 DM'li hastaları özelliklerine göre riskleri belirlemek yönetim için ilk yaklaşım olabilir. Ramazan öncesindeki son 3 ay içerisinde diyabetik acil durum gelişmesi, hipoglisemiyi algılayamama, kötü glisemik kontrol, insülinle tedavi edilen pregestasyonel DM veya gestasyonel DM, evre 4-5 böbrek KBH, makrovaskülerkomplikasyonların varlığı, geriatrik ve kırılgan hastalar çok yüksek riskli olarak değerlendirilebilir (5-7). Orta derece hiperglisemi (ortalama kan şekeri $150-300 \mathrm{mg} / \mathrm{dL}$ veya $\mathrm{HbA} 1 \mathrm{C}$ değeri \%7,5-9 aras1), iyi kontrollü Tip $1 \mathrm{DM}$, çoklu doz karışım insülinlerle iyi kontrol altındaki tip $2 \mathrm{DM}$, diyetle kontrol altında olan pregestasyonel DM veya gestasyonel DM, evre $3 \mathrm{KBH}$, stabil makrovasküler hastalık varlığı, aşırı fiziksel aktivite gerektiren bir işte çalışanlar, yalnız yaşayıp insulin veya sülfonilüre ile tedavi edilenler, ek risk faktörü olabilecek ko-morbid hastalıkları olanlar, mental durumu etkileyen ilaç kullananlar yüksek riskli olarak değerlendirilebilir $(5,7)$.

Yaşam tarzı değişikliği, metformin, yeni kuşak sülfonilüre, kısa etkili insulin sekretagogları, akarboz, tiazolidinedionlar, SGLT-2 inhibitörleri, inkretin bazlı ilaçlar veya bazal insülin tedavilerinden bir veya birkaçı ile kan şekeri kontrol altında olan ve ek komorbiditeleri olmayan tip 2 DM'liler düşük derecede riskli olarak kabul edilmektedir ve pek çok hekim bu hasta grubunun oruç tutmasında sakınca görmemektedir (7)

Biz de bu yazıda kendi isteği ile oruç tutacağını beyan eden ve oruç tutan üç tip 2 diyabet hastasının takip sonuçlarını paylaşmak istedik.

\section{OLGULAR}

\section{Olgu 1}

Elli dokuz yaşında bayan hastanın 15 yıldır tip $2 \mathrm{DM}$ ve hipertansiyon tanisı mevcuttu. İlk poliklinik başvurusunda $16 \mathrm{U} /$ gün detemir insülin, vildagliptin+metformin 50/1000 mg 2x1/gün ve irbesartan+ hidroklortiyazid 1x1/gün kullanımı mevcut idi. Hastada diyabetik nöropati, retinopati ve kalp yetersizliği yoktu. En son yapılan ekokardiyografisinde (EKO) EF \%60 idi. Hastanın gelişinde HbA1C: \%6,9, açlık kan şekeri: $133 \mathrm{mg} / \mathrm{dl}$, üre: 23 $\mathrm{mg} / \mathrm{dl}$, serum kreatinin: $0,62 \mathrm{mg} / \mathrm{dl}$, TSH: $1,17 \mu \mathrm{U} /$ ml, sT4: 1,33 ng/dl idi. Daha önce gittiği doktoru tarafından insülin kullandığı için oruç tutmasının uygun olmayacağ1 söylenen hasta, insülin kullanmayı bırakıp oruç tutmak isteği ile polikliniğimize başvurdu. Düşük risk grubunda olarak değerlendirilen hastaya vildagliptin+metformin $50 / 1000 \mathrm{mg}$ $2 \times 1 /$ gün devam edildi, insülin detemir kesilerek yerine dapagliflozin $10 \mathrm{mg} 1 \mathrm{x} 1 \mathrm{tb} /$ gün eklendi. Henüz oruç tutmuyor iken 3 günlük kan şekeri takibi ile polikliniğe kontrole geldi (Tablo 1).

İnsülin tedavisi kesilmesi sonrası düzenlenen tedavi ile kan şekerlerinin istenen aralıklarda gittiği görülen hastada uzun açlık süresi de düşünülerek oruç tutacağ 1 dönem için dapaglifflozin kesildi ve sadece vildagliptin + metformin $2 \times 1$ şeklinde kullanmas önerildi. Hastaya oruç tutarken öğlen ve iftardan hemen önce olmak üzere açlık, iftar sonrası tokluk olmak üzere 3 günlük kan şekeri takibi ile kontrol önerildi. Hastanın oruçlu iken takiplerinde kan şekerleri düzenli seyretti (Tablo 2). Daha sonraki vizitlerinde açlık kan şekerleri 100 civarında tokluk kan şekerleri $100-150 \mathrm{mg} / \mathrm{dl}$ civarında seyrettiği ve hiç hipoglisemisinin olmadığı görüldü.

Tablo 2. Hastanın oruçlu iken 3 günlük kan şekeri profili

\begin{tabular}{|l|c|c|c|}
\hline & Öğlen aç & Akşam aç & $\begin{array}{c}\text { iftardan 2 saat } \\
\text { sonra tokluk }\end{array}$ \\
\hline 1. gün & 132 & 134 & 165 \\
\hline 2. gün & 142 & 123 & 153 \\
\hline 3. gün & 110 & 105 & 141 \\
\hline
\end{tabular}

Tablo 1. Hastanın oruç öncesi 3 günlük kan şekeri profili

\begin{tabular}{|l|c|c|c|c|c|c|c|}
\hline & Sabah aç & Sabah tok & Öğlen aç & Öğlen tok & Akşam aç & $\begin{array}{c}\text { iftardan 2 saat } \\
\text { sonra tokluk }\end{array}$ & $\begin{array}{c}\text { Sahurdan 2 saat } \\
\text { sonra tokluk }\end{array}$ \\
\hline 1.gün & 130 & 129 & 139 & 147 & 110 & 135 \\
\hline 2.gün & 124 & 155 & & 158 & 95 & 162 \\
\hline 3.gün & 132 & 160 & 165 & 142 & 103 & 162 & 144 \\
\hline
\end{tabular}




\section{Olgu 2}

Altmış yaşında erkek hastanın 2 yıldır tip 2 DM ve 5 yıldır hipertansiyonu vardı. Hasta valsartan+hidroklorotiyazid 160/12,5 $\mathrm{mg}$ tb/g, metformin+sitagliptin 1000/50 mg 2x1 tb/g, dapagliflozin $10 \mathrm{mg} 1 \mathrm{x} 1 \mathrm{tb} / \mathrm{g}$ kullaniyordu. Diyabetik retinopatisi olmayan, diyabetik polinöropati nedeni ile alfa lipoik asit 6 aydır kullanan hasta oruç tutmak istediği için polikliniğe başvurdu. En son ölçülen HbA1C: \%6,7, üre: $35 \mathrm{mg} / \mathrm{dl}$, kreatinin: $1,17 \mathrm{mg} /$ dl, eGFR $54 \mathrm{ml} / \mathrm{dk}$ olan hasta evre 3 kronik böbrek hastalığı (KBH) idi ve yüksek riskli olarak değerlendirildi. Hastanın Ramazan öncesi kan şekeri takipleri $82-168 \mathrm{mg} / \mathrm{dl}$ arasında değişmekteydi. Ramazan başladığı zaman dapagliflozin tedavisi kesildi, metformin+ sitagliptin sadece iftarda 1 tb alacak şekilde ayarland1. Daha sonraki vizitlerinde açlık kan şekerleri 90-120 mg/dl civarında; tokluk kan şekerleri $100-150 \mathrm{mg} / \mathrm{dl}$ civarında seyrettiği ve hiç hipoglisemisinin olmadığı görüldü (Tablo 3).

Tablo 3. Hastanın oruçlu iken 3 günlük kan şekeri profili

\begin{tabular}{|l|c|c|c|}
\hline & Öğlen aç & Akşam aç & $\begin{array}{c}\text { iftardan 2 saat } \\
\text { sonra tokluk }\end{array}$ \\
\hline 1. gün & 105 & 134 & 125 \\
\hline 2. gün & 102 & 143 & 133 \\
\hline 3. gün & 95 & 105 & 111 \\
\hline
\end{tabular}

\section{Olgu 3}

Elli yaşında bayan hasta, 12 yıl önce tip $2 \mathrm{DM}$ tanıs1 almış. Kendisi doktor gözetimi olmadan oruç tuttuğunda parmak ucu kan şekerini $90 \mathrm{mg} / \mathrm{dl}$ olarak ölçmesi üzerine, doktor gözetimi altında oruç tutmak amaciyla polikliniğimize başvurdu. Hasta insülin glarjin 24 Ü/gün, insülin aspart 9/9/9 Ü/gün şeklinde günde 4 kez insülin kullanıyordu. Oruç tutarken sahur ve iftarda bolus insülinlerini yapmaya devam etmiş. Hastanın tetkiklerinde HbA1C: \%13, açlık kan şekeri: $199 \mathrm{mg} / \mathrm{dl}$, total kolesterol: $239 \mathrm{mg} /$ dl, LDL kolesterol: $143 \mathrm{mg} / \mathrm{dl}$, trigliserit: $279 \mathrm{mg} / \mathrm{dl}$, üre: $20 \mathrm{mg} / \mathrm{dl}$, serum kreatinin: $0,62 \mathrm{mg} / \mathrm{dl}$ olarak geldi. Bazal-bolus insülin tedavisi kullanan ve kontrolsüz kan şekeri olan hasta çok yüksek riskli olarak değerlendirildi. Oruç tutmaması gerektiği söylenmesine rağmen oruç tutmak istediğini bildirdi. Glarjin ve aspart insülinleri kesildi, metformin+sitagliptin

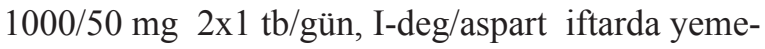
ğin başında 30 Ü/gün olacak şekilde başlandı. Hasta oruçlu iken 3 günlük kan şekeri takibi (Tablo 4) ile geldi.
Tablo 4. Hastanın oruçlu iken 3 günlük kan şekeri profili

\begin{tabular}{|l|c|c|c|c|}
\hline & $\begin{array}{c}\text { Sahurdan 2 } \\
\text { saat tokluk }\end{array}$ & $\begin{array}{c}\text { Öğlen } \\
\text { aç }\end{array}$ & $\begin{array}{c}\text { Akşam } \\
\text { aç }\end{array}$ & $\begin{array}{c}\text { iftardan 2 saat } \\
\text { sonra tokluk }\end{array}$ \\
\hline 1. gün & 228 & 143 & 79 & 235 \\
\hline 2. gün & 150 & 102 & 104 & 133 \\
\hline 3. gün & 176 & 90 & 105 & 211 \\
\hline
\end{tabular}

Hastanın açlık kan şekerlerinin en fazla $79 \mathrm{mg} / \mathrm{dl}$ civarına kadar düştüğü dikkati çekti ama hasta sorgulandığında hiç hipoglisemik semptom tariflemedi. Tokluk kan şekerleri ise bazı ölçümlerde $200 \mathrm{mg} /$ dl üzerine çıkmıştı. Açlık kan şekerlerindeki düşük değerler nedeniyle bazal insülinin azaltılması düşünüldü ve Ideg-aspart $18 \mathrm{U} / \mathrm{g}$ olarak düzenlendi. Ideg-aspart dozu azaltılınca kısa etkili insülin dozu da azalmış olduğundan, tokluk kan şekerini kontrol altına alabilmek için dapagliflozin $10 \mathrm{mg}$ tb $1 \times 1$ /gün olarak iftarda alması söylenerek tedaviye eklendi ve 3 gün sonra kan şekeri takipleri ile (Tablo 5) tekrar görüldü.

Açlık kan şekeri düzeylerinin 90-130 $\mathrm{mg} / \mathrm{dl}$ civarında seyrettiği ve daha iyi gittiği, dapagliflozin etkisi ile hastanın tokluk kan şekerlerinin de düzene girdiği görüldü.

Tablo 5. Hastanın 3 günlük kan şekeri profili

\begin{tabular}{|l|c|c|c|c|}
\hline & $\begin{array}{c}\text { Sahurdan 2 saat } \\
\text { sonra tokluk }\end{array}$ & $\begin{array}{c}\text { Öğlen } \\
\text { aç }\end{array}$ & $\begin{array}{c}\text { Akşam } \\
\text { aç }\end{array}$ & $\begin{array}{c}\text { iftardan 2 saat } \\
\text { sonra tokluk }\end{array}$ \\
\hline 1. gün & 158 & 130 & 94 & 242 \\
\hline 2. gün & 177 & 110 & 98 & 188 \\
\hline 3. gün & 133 & 111 & 89 & 140 \\
\hline
\end{tabular}

\section{TARTIŞMA}

Tip 2 DM hastalarının oruç tutması konusu birçok tartışmaya neden olmuştur. Farklı ekollere göre diyabetik hastalarda oruç tutulması görüşü tamamen farkl11ık göstermektedir. Ancak bu durum dini bir realite olup toplumdan soyutlanması mümkün degildir. En son k1lavuzlar bu durumun hekim camias1 ve dini otoritenin ortak kararıly hareket edilmesini önermiştir. Bu durumda hekime düşen risklerin belirlenmesi, uygun hasta seçimi ve takibin yapılması olmalıdır. Amerikan Diyabet Derneği'nin yayınladığı bir raporda hastalarda risk değerlendirmesi yapılarak hipoglisemi, hiperglisemi, diyabetik ketoasidoz, dehidratasyon ve tromboz gibi istenmeyen durumların önlenmesi hedeflenmesi önerilmiştir. Bunun için hastaların bireyselleştirilerek muhakkak Ramazan öncesi eğitimlerinin tamamlanması, nutrisyonel ve egzersiz planlamalarının yapılması, ilaç yönetiminin yapılması ve çok sıkı kan şekeri takibi yapılması önerilmektedir (3). 
El Toony ve ark. (5)'nın yapmış olduğu ve eğitimin önemini vurgulayan bir çalışmada 320 tip 2 DM'li hastada eğitim alan grupta eğitim almayan gruba göre anlamlı glisemik ve metabolik kontrol sağlandığ1 görülmüştür.

Bashir ve ark. (6)'nın yaptığı güncel bir çalışmada aktif yaşayan tip 2 DM'li hastalarla sedanter yaşayan hastalar oruç süresince devamlı glukoz monitorizasyonuyla takip edilmiş, aktif grupta glisemik kontrol daha iyiyken, hipoglisemi daha fazla görülmüştür.

Hejaili ve ark. (9), çalışmalarının sonuçlarına göre KBH (hafif-orta derecede) ve renal transplantlı hastaların oruç tutabileceğini ve böbrek fonksiyonlarında bozukluk veya progresyon olmayacağını belirtmişler, Boobes ve ark. (10)'nın yaptığı çalışma da bunu desteklemiştir.

Bizim 3 olgumuz irdelendiğinde, 1. olgumuz düşük risk, 2. olgumuz yüksek risk, 3. olgumuz çok yüksek risk grubunda olarak değerlendirildi. Hastalar1mız kendi istekleriyle oruç tutmak istediklerini ve uygun tedavi almak istediklerini beyan etmişlerdi. Hastalara riskleri anlatıldı, eğitimleri verildi ve kan şekeri yakın takibiyle kontrole çağrıldı. Hastaların profilleri incelendiğinde oruç esnasında herhangi bir istenmeyen olay yaşanmadi. Kan şekerleri düzenli seyretti. Olgu 3'ün kan şekerleri Ramazan öncesinden daha düzenli seyretti. Bu durum yakın takibe, uygun hasta seçimine ve hasta eğitimine bağlı olabilir. Bu durum hasta motivasyonu ve tedavinin devamı için de önemli olmaktadır.

Son dönemde yaygın olarak kullanılan sodyum glukoz ko-transporter 2 (SGLT-2) inhibitörleri ile yapılan çalışmalarda güvenli olabileceği, hastalarda ketonemi, asidoz ve hipogliseminin artmadığı güncel bir çalışmada gösterilmiştir (11). Ancak diğer bir çalışmada SGLT-2 inhibitörlerinin insülin tedavisiyle birlikte kullanılmasının hastane yatışı gerektirmeyen hipoglisemilere yol açabileceği ve bu konuda dikkatli olunması gerektiğini göstermiştir (12). Tedavi yönetiminin en önemli kısmını hastaya uygun tedavi seçimi ve doz ayarlaması oluşturmaktadır. Bununla ilgili doz ayarlama şemalarını öneren yeni kılavuzlar yayımlanmaya başlamıştır (7).

Mohsen ve ark. (13) koroner arter hastalığ1, metabolik sendrom ya da serebrovasküler hastalık öyküsü olan 38 erkek ve 44 kadın, 29-70 yaş (ortalaması $54.0 \pm 10$ yıl) olan 82 gönüllü üzerinde yaptıkları çalışmada, takiplerde bu kişilerin Ramazan ayında oruç tutmaları sonrası kardiyovasküler morbidite ve mortalitelerinde artış olmadığ1 görülmüştür. Hatta çalışma sonucunda, daha önce kardiyovasküler hastalık öyküsü olan olgularda 10 yıllık koroner kalp hastalığ1 risk skoru ve lipid profili, sistolik kan basınc1, kilo, vücut kitle indeksi ve bel çevresi gibi diğer kardiyovasküler risk faktörlerinde anlamlı bir iyileşme olduğunu tespit etmişlerdir.

Tıbbi açıdan oruç tutabilecek veya oruç tutması önerilmediği halde oruç tutmak isteyen hastalar (diyabet başta olmak üzere, hipertansiyon $\mathrm{KBH}$, kalp yetmezliği, gastrointestinal sistem problemi olanlar vs.) Ramazan öncesinde ve Ramazan süresince karş1laşabileceği problemler konusunda eğitilmelidirler. Kan şekeri ölçümünün gerekli olduğu ve orucu bozmayacağı vurgulanmalı, diyet, egzersiz ve ilaç dozlarının oruca göre ayarlanması gerektiği konusunda bilgilendirilmeli, kan şekerinin aşırı düşmesi $(\leq 70 \mathrm{mg} / \mathrm{dl})$ veya aşırı yükselmesi ( $\geq 300 \mathrm{mg} / \mathrm{dl})$ halinde hayati tehlike doğacağından tıbbi ve dini açıdan orucunu bozması gerektiği konusunda bilgilendirilmelidir $(7,8)$.

Sonuç olarak; oruçlu olunan süre 8 saatten 20 saate kadar uzayabilmekte, bazı kişiler bu süreyi evde serin ortamda geçirirken bazı kişiler sıcakta ve aktif fiziksel aktivite altında olabilmektedir. $\mathrm{Bu}$ nedenle oruç için hastaların kişisel özellikleri, ek hastalıkları, yaşantıları, fiziksel aktiviteleri de dikkate alınarak, oruç tutmak isteyen kişilerde hekimler tarafından bireysel karar verilmelidir.

\section{MADDI DESTEK VE ÇIKAR ILIŞKISi}

Çalışmayı maddi olarak destekleyen kişi/kuruluş yoktur ve yazarların çıkara dayalı bir ilişkisi yoktur.

\section{ETIK DURUM}

Helsinki İlkeler Deklarasyonu etik ilkelerine uyulmuştur, hastalardan onam alınmıştır.

\section{KAYNAKLAR}

1. https://www.sabah.com.tr/fotohaber/yasam/hangiulkede-kac-saat-oruc-tutuluyor-en-uzun-sure-oructutulan-ulke-hangisi/2.

2. Bravis V, Hui E, Salih S, et al. Ramadan education and awareness in diabetes (READ) programme for muslims with Type 2 diabetes who fast during Ramadan. Diabet Med 2010; 27: 327-31.

3. Al-Arouj M, Assaad-Khalil S, Buse J, et al. Recommendations for management of diabetes during Ramadan: update 2010. Diabetes Care 2010; 33: 1895902.

4. Hassanein M, Al-Arouj M, Ben-Nakhi A, et al. Diabetes and Ramadan: Practical Guidelines. IDF, in Collaboration with the Diabetes and Ramadan (DAR) International Alliance, April 2016.

5. El Toony LF, Hamad DA, Omar OM. Outcome of focused pre-Ramadan education on metabolic and glycaemic parameters in patients with type 2 diabetes mellitus. Diabetes Metab Syndr 2018 Apr 25. pii: S18714021(18)30141-3. doi: 10.1016/j.dsx.2018.04.036. [Epub ahead of print].

6. Bashir M, Elhadd T, Ali H, et al. A pilot study using flash continuous glucose monitoring in patients with type 2 diabetes on multiple antidiabetic agents during Ramadan. Diabetes Metab Syndr 2018 Jun 
7. pii: S1871-4021(18)30210-8. doi: 10.1016/j. dsx.2018.06.005. [Epub ahead of print].

7. Özkara A, Ateș İ, Altay M. https://www.medimagazin. com.tr/guncel/genel/tr-hekimler-icin-oruc-tutmakisteyen-diabet-hastalarina-yonelik-bilimseldegerlendirme-ve-takip-kilavuzu-11-681-77088.html.

8. Demir ME. Böbrek hastaları ve oruc ibadeti. J Health Sci Med 2018; 1: 21-2.

9. Hejaili F, Qurashi S, Binsalih S, Jaradt M, Al Sayyari A. Effect of repeated ramadan fasting in the hottest months of the year on renal graft function. Nephrourol Mon 2014 Mar 1; 6:e14362. doi: 10. 5812/numonthly. 14362. eCollection 2014 Mar.

10. Boobes Y, Bernieh B, Al Hakim MR. Fasting Ramadan in kidney transplant patients is safe. Saudi J Kidney Dis Transpl 2009; 20: 198-200.

11. Shao Y, Lim GJ, Chua CL“"The effect of Ramadan fasting and continuing sodium-glucose co-transporter-2 (SGLT2) inhibitor use on ketonemia, blood pressure and renal function in Muslim patients with type 2 diabetes. Diabetes Res Clin Pract 2018; 142: 85-91. doi: 10.1016/j. diabres.2018.05.022. [Epub ahead of print].

12. Bashier A, Khalifa AA, Abdelgadir EI, et al. Safety of sodium-glucose cotransporter inhibitors (SGLT2-I) during the month of Ramadan in Muslim patients with type 2 diabetes. Oman Med J 2018; 33: 104-10.

13. Nematy M, Alinezhad-Namaghi M, Rashed MM, et al. Effects of Ramadan fasting on cardiovascular risk factors: a prospective observational study. Nutrition J 2012; 11: 69 